\title{
PENGEMBANGAN APLIKASI VIRTUAL REALITY 3D PENGENALAN MANUSIA PURBA BANGSA INDONESIA UNTUK SMA KELAS X (STUDI KASUS SMA NEGERI 2 SINGARAJA)
}

\author{
Nyoman Jaya Wardhana ${ }^{1}$, I Ketut Resika Arthana ${ }^{2}$, Dewa Gede Hendra Divayana ${ }^{3}$ \\ ${ }^{123}$ Jurusan Pendidikan Teknik Informatika/FTK/UNDIKSHA \\ Singaraja, Indonesia
}

e-mail: jwardhana8@gmail.com ${ }^{1}$, resika@undiksha.ac.id², hendra.divayana@undiksha.ac.id ${ }^{3}$

\begin{abstract}
Abstrak
Informasi yang diperoleh oleh siswa maupun guru Sejarah SMA terkadang hanya berupa gambar ilustrasi yang tidak cukup menggambarkan bagaimana kehidupan manusia purba di Indonesia. Oleh sebab itu, peneliti memanfaatkan teknologi Virtual reality sebagai media penyampaian informasi agar proses pembelarajan menjadi semakin menarik. Tujuan penelitian ini adalah: (1) Untuk mengembangkan Aplikasi Virtual reality 3D Pengenalan Manusia Purba bangsa Indonesia untuk kelas X. (2) Untuk mengetahui respon siswa kelas $X$ terhadap implementasi Aplikasi Virtual reality 3D Pengenalan Manusia Purba bangsa Indonesia. Pengembangan aplikasi ini menggunakan model ADDIE. Subjek penelitian ini yaitu siswa kelas X SMA Negeri 2 Singaraja. Terdapat 3 (tiga) pengujian pada penelitian ini, pengujian tersebut diantaranya yaitu uji pemahaman siswa, uji respon pengguna dan uji pengalaman pengguna. Pengujian untuk mengetahui pemahaman siswa dilakukan dengan pemberian pretest dan postest dan didapatkan nilai $\mathrm{N}$-Gain sebesar 0.4 yang masuk kriteria sedang. Pengujian untuk mengetahui respon siswa setelah menggunakan aplikasi ini dilakukan dengan metode angket dan memiliki hasil dengan persentase rata-rata sebesar $82,3 \%$ yang artinya aplikasi masuk kategori sangat baik. Selain itu juga dilakukan pengujian pengalaman pengguna. Pengujian ini dilakukan dengan menggunakan User Experience Quistionneir (UEQ) dengan hasil daya tarik dan stimulasi memiliki nilai excellent sedangkan kejelasan, efisiensi, ketepatan dan kebaruan memiliki nilai good.
\end{abstract}

Kata kunci: Virtual reality, Manusia Purba Indonesia, 3D, Cardboard

\begin{abstract}
Information obtained by high school students and history teachers is sometimes only in the form of illustrations that not enough to describe how ancient humans lived in Indonesia. Therefore, researchers use Virtual reality technology as a medium for delivering information so that the learning process becomes more interesting. The purpose of this research is: (1) To develop the virtual reality application of indonesian ancient human for high school $X$ class. (2) To find out the response of class $X$ students to the implementation of the virtual reality application of indonesian ancient human. The research of this application uses the ADDIE model. The subject of this research is high school $X$ Class in SMA Negeri 2 Singaraja. There are 3 (three) tests in this study, the tests of which include student understanding test, user response test and user experience test. The test to find out students understanding is done by giving pre-test and post-test and obtained an N-Gain value of 0.4 which is categorized as medium. The test to find out the response of students after using this application is done by questionnaire method and has results with an average percentage of $82.3 \%$ which means the application is in a very good category. In addition, user experience testing is also carried out. This test is done by using User Experience Queryion (UEQ) with the results of attraction and stimulation having excellent values while clarity, efficiency, accuracy and novelty have good value.
\end{abstract}

Keywords : Virtual reality, Indonesian Ancient Human, 3D, Cardboard 


\section{PENDAHULUAN}

Penelitian manusia purba telah dimulai sejak lama. Kehidupan awal manusia dipelajari melalui peninggalan-peninggalan yang ditemukan berbagai daerah di dunia. Manusia purba yang ditemukan di Indonesia memiliki jenis yang berbeda-beda [1]. Fosil manusia purba Indonesia ditemukan di daerah Sangiran, Trinil dan beberapa daerah lain. Penemuan tersebut berupa tengkorak manusia dan beberapa peralatan seperti kapak genggam dan batu asahan yang di gunanakan oleh manusia purba pada zaman tersebut [2].

Peninggalan yang hanya berupa tengkorak dan beberapa benda lain menyebabkan kurangnya pengetahuan tentang bagaimana lingkungan dan kehidupan manusia purba tersebut. Pembelajaran manusia purba akan didapatkan siswa Kelas X SMA pada Kompetensi Dasar Menganalisis kehidupan manusia purba dan asal-usul nenek moyang bangsa Indonesia. Dalam pembelajaran tersebut hanya diperlihatkan gambaran berupa fosil maupun gambaran 2 dimensi sebagai media penyampaian informasi.

Berdasarkan hasil wawancara dengan guru sejarah di SMA Negeri 2 Singaraja, beliau menyatakan bahwa pembelajaran sejarah di SMA saat ini lebih berpusat pada siswa. Artinya siswa lebih aktif dalam mencari materi pembelajaran. Informasi yang kebanyakan diperoleh beliau maupun para siswa dari internet terkadang hanya berupa gambar ilustrasi yang tidak cukup menggambarkan bagaimana kehidupan manusia purba di Indonesia.

Solusi dari permasalahan tersebut adalah dengan cara memanfaatkan teknologi sebagai media penyampaian informasi agar proses pembelarajan menjadi semakin menarik. Salah satunya ialah teknologi Virtual reality (VR) yang saat ini sedang berkembang dan menjadi trend. Teknologi Virtual reality dapat berjalan pada komputer desktop ataupun mobile, salah satu framework open source yang mendukung pengembangan Virtual reality adalah Google VR SDK yang dikembangkan oleh google untuk memberikan kesempatan pada developer untuk mengembangkan aplikasi berbasis VR. Penggunaan Virtual reality juga tidak menggunakan biaya yang terlalu mahal dan alat pendukung penggunaan VR juga mudah di dapatkan.

Pemanfaatan teknologi VR dalam dunia pendidikan telah pernah diteliti sebelumnya oleh Sunarni dan Budiarto [3] dalam artikelnya yang berjudul Persepsi Efektivitas Pengajaran Bermedia Virtual reality (VR). Dari penelitian tersebut didapatkan bahwa dalam pembelajaran sebuah materi yang harus didukung oleh visualisasi, praktik dan sumberdaya maka pengguna media VR sangatlah mendukung, selain itu keinginan dari responden (Dosen) cenderung sangat tinggi, $(92,3 \%)$ terhadap penggunaan teknologi VR dalam pembelajaran ke depannya. Penelitian lainnya yaitu penelitian dengan judul Game Edukasi "Penjelajah" Berbasis Virtual reality [4]. Pada penelitian ini penulis mengambil contoh bagaimana penerapan penggunaan Virtual reality di lingkungan sekolah dengan menyesuaikan kelas maupun mata pelajaran yang terkait. Selanjutnya penelitian dengan judul penelitian Pengembangan Virtual reality Pengenalan Kendaraan Untuk Anak Usia Dini (Studi Kasus: Tk Negeri Pembina Singaraja) [5]. Pada penelitian penulis mencontoh pengujian yang dilakukan peneliti tersebut agar nantinya aplikasi yang di buat penulis menjadi semakin lebih baik. Penelitian terakhir adalah penilitian yang dengan judul penelitian Pembuatan Ruang Pamer 3D Museum Sangiran Menggunakan Teknologi Virtual reality berbasis Android [6]. Pada penelitian ini penulis juga dapat melihat pengujian di yang telah dilakukan pada beberapa perangkat android.

Berdasarkan paparan dan hasil penelitian sebelumnya, peneliti tertarik untuk mengembangkan dan menghasilkan rancangan sebuah aplikasi Virtual reality untuk mengenalkan manusia purba bangsa Indonesia dalam bentuk penelitian berjudul "Pengembangan Aplikasi Virtual reality 3D Pengenalan Manusia Purba bangsa Indonesia untuk SMA Kelas $X$ (Studi Kasus SMA Negeri 2 Singaraja)". Dengan adanya pengembangan aplikasi Virtual reality $3 D$ ini diharapkan agar siswa SMA lebih tertarik untuk mempelajari mengenai manusia purba yang pernah ada di Indonesia. 


\section{KAJIAN TEORI}

a. Manusia Purba

Manusia Purba (Prehistoric People) merupakan jenis manusia yang hidup berjuta tahun lalu yang belum mengenal tulisan [2]. Manusia purba diperkirakan hidup di bumi sejak zaman neolitiukum. Terungkapnya manusia purba ini berawal dari penemuan fosil dan artefak. Fosil adalah tulang belulang manusia maupun hewan dan tumbuhan yang telah membatu sedangkan artefak adalah peralatan dan perlengkapan kehidupan manusia sebagai hasil dari kebudayaannya.

Dari penemuan fosil dan artefak ini para peneliti dapat mengetahui usia dan peradaban di alam kehidupanya pada masa lampau.

Terdapat bebera jenis manusia purba yang pernah berkembang di Indonesia, jenis tersebut diantaranya yaitu jenis Meganthropus Paleojavanicus, jenis Pithecanthropus dimana terbagi menjadi Pithecanthropus Erectus, Pithecanthropus Mojokertensis, Pithecanthropus Robustus dan Pithecanthropus Soloensis serta jenis Homo Sapiens yang terbagi menjadi Homo Soloensis, Homo Wajakensis dan Homo Floresiensis

\section{b. Virtual reality}

Virtual reality adalah sebuah teknologi yang membuat pengguna atau user dapat berinteraksi dengan lingkungan yang ada dalam dunia maya yang disimulasikan oleh komputer, sehingga pengguna merasa berada di dalam lingkungan tersebut [7]. Di dalam bahasa Indonesia Virtual reality dikenal dengan istilah realitas maya. Kelebihan utama dari Virtual reality adalah pengalaman yang membuat user merasakan sensasi dunia nyata dalam dunia maya.

Teknologi Virtual reality sejatinya telah banyak diterapkan di beberapa sektor industri seperti kedokteran, penerbangan, pendidikan, arsitek, militer, hiburan dan lain sebagainya. Virtual reality sangat membantu dalam mensimulasikan sesuatu yang sulit untuk dihadirkan secara langsung dalam dunia nyata.

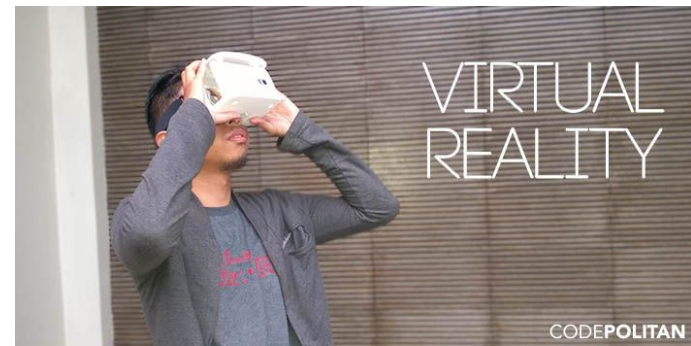

Gambar 1. Penggunaan Virtual reality

\section{METODE}

a. Jenis dan Model Penelitian

Pengembangan Aplikasi Virtual reality

3D Pengenalan Manusia Purba bangsa Indonesia untuk Kelas X SMA (Studi Kasus SMA Negeri 2 Singaraja) ini termasuk penelitian pengembangan Research and Development (R\&D). Menurut Sugiyono "Penelitian Research and Development (R\&D) adalah metode penelitian yang digunakan untuk menghasilkan produk tertentu dan menguji keefektifan produk tersebut" [8]. Metode penelitian ini menekankan kemampuan penelitian dalam membuat suatu produk baik berupa materi, media, alat dan strategi pembelajaran atau maupun rekayasa pendidikan. Model yang digunakan dalam penelitian ini adalah ADDIE.

\section{b. Model Pengembangan}

Dalam penelitian pengembangan model ADDIE, akan dilakukan 5 tahapan. Lima tahapan tersebut diantaranya yaitu Analyze, Design, Development, Implementation dan Evaluation. Gambaran mengenai model ADDIE dan pengujian yang akan dilakukan dalam Pengembangan Aplikasi Virtual reality $3 D$ Pengenalan Manusia Purba bangsa Indonesia untuk Kelas X SMA (Studi Kasus SMA Negeri 2 Singaraja) dapat dilihat pada Gambar 2.

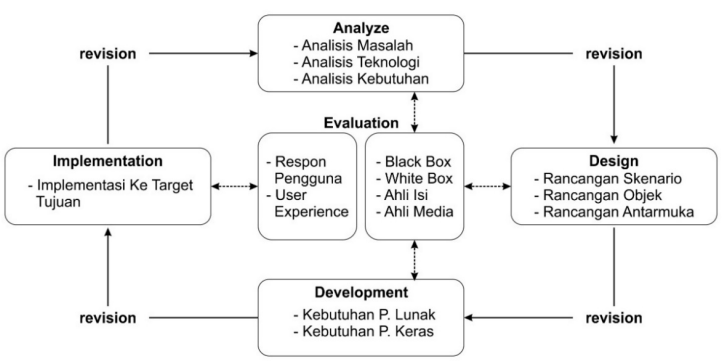

Gambar 2. Tahapan ADDIE pada Aplikasi yang dikembangkan 
Tahap pertama dari model ADDIE adalah tahap analisis, menganalisis permasalahan dan kebutuhan dari aplikasi Virtual reality $3 D$ Pengenalan Manusia Purba bangsa Indonesia untuk Kelas X SMA dengan mencari dan mengumpulkan data dari berbagai sumber. Pada aplikasi ini pemain akan berinteraksi dengan dunia virtual dengan tujuan untuk mempelajari jenis manusia purba yang ada di Indonesia.

Tahap kedua adalah tahap desain (design), pada tahap ini dirancang skenario aplikasi, perancangan objek manusia purba dan antarmuka dari aplikasi ini serta perancangan evaluasi. Tahapan selanjutnya adalah tahap development atau tahap pengembangan. Pada tahap ini pengembang mulai merealisasikan konsep dari aplikasi pada tahap-tahap sebelumnya. Untuk merealisasikan konsep tersebut dibutuhkan perangkat lunak maupun perangkat keras sehingga aplikasi dapat dibentuk. Adapun perangkat lunak yang diperlukan seperti Blender, Adobe Photoshop, Audacity dan Unity 3D, sedangkan untuk perangkat keras dibutuhkan perangkat komputer atau laptop, smartphone dan cardboard untuk mencoba aplikasi.

Tahap Implementation adalah tahap dimana aplikasi telah siap untuk diperkenalkan dan dilakukan pengujian kelayakan. Pada tahap ini peneliti akan melakukan implementasi aplikasi Virtual reality $3 D$ Pengenalan Manusia Purba bangsa Indonesia untuk SMA kelas $X$ di SMA Negeri 2 Singaraja Singaraja. Aplikasi akan diterapkan saat mata pelajaran sejarah tentang awal kehidupan manusia Indonesia dimana didalamnya juga membahas mengenai manusia purba. Pada tahap juga akan dilakukan beberapa pengujian seperti uji pemahaman siswa, respon pengguna dan uji user experience.

Tahapan selanjutnya dari pengembangan aplikasi Virtual reality $3 D$ Pengenalan Manusia Purba bangsa Indonesia adalah Evaluation (evaluasi). Evaluasi adalah kegiatan untuk mengumpulkan, memahami dan melaporkan hasil dari analisis tentang suatu program sehingga hasilnya dapat dijadikan pertimbangan untuk melihat apakah program layak digunakan [9]. Tahapan ini bertujuan untuk mengetahui tentang adanya kesalahan atau kekurangan dari aplikasi yang di kembangkan, sehingga aplikasi masih dapat diperbarui sehingga layak untuk di rilis ke masyarakat luas.

Ada beberapa pengujian yang dilakukan pada tahap evaluasi, diantaranya yaitu Uji Blackbox, Uji Whitebox, Uji Ahli Media, Uji Ahli Isi, Uji UX (User Experience) dan Uji respon pengguna. Pengujian tersebut dilakukan di tiap tahap pada metode ADDIE. Uji blackbox, uji ahli media, uji ahli isi dan respon pengguna menggunakan skala likert. Adapun bobot dari uji ahli isi, uji ahli media dan uji respon pengguna dengan status pernyataan negatif dan positif dapat dilihat pada Tabel 1.

Tabel 1. Tabel Bobot Pernyataan [10]

\begin{tabular}{ccc}
\hline \multirow{2}{*}{ Alternatif } & \multicolumn{2}{c}{ Pernyataan } \\
\cline { 2 - 3 } & Positif & Negatif \\
\hline SS & 5 & 1 \\
\hline S & 4 & 2 \\
\hline CS & 3 & 3 \\
\hline TS & 2 & 4 \\
\hline STS & 1 & 5 \\
\hline
\end{tabular}

Perhitungan presentase masing-masing subyek menggunakan Rumus [10] berikut:

Persentase $=\frac{\sum(\text { Jawaban } \times \text { Bobot Tiap Soal })}{\mathrm{n} \times \text { Bobot Tertinggi }} \times 100 \%$

Kemudian mencari presentase keseluruhan subyek digunakan Rumus [10] berikut:

Persentase $=\frac{\text { jumlah Persentase keseluruan subyek }}{\text { Banyak Subyek }}$

Setelah melakukan perhitungan terhadap angket yang telah diberikan penilaian, maka kriteria penilaian dari nilai yang didapat dapat dijabarkan seperti pada Tabel 2.

Tabel 2. Tabel Kategori Persentase [10]

\begin{tabular}{ccl}
\hline No & Persentase & \multicolumn{1}{c}{ Kategori } \\
\hline $\mathbf{1}$ & $80 \%-100 \%$ & $\begin{array}{l}\text { Sangat (Sesuai/Baik/ } \\
\text { Suka) }\end{array}$ \\
\hline $\mathbf{2}$ & $60 \%-79,99 \%$ & (Sesuai/Baik/Suka) \\
\hline
\end{tabular}




\begin{tabular}{ccl}
\hline $\mathbf{3}$ & $40 \%-59,99 \%$ & Cukup/Netral \\
\hline $\mathbf{4}$ & $20 \%-39,99 \%$ & $\begin{array}{l}\text { Tidak (Sesuai/ Kurang } \\
\text { baik) }\end{array}$ \\
\hline $\mathbf{5}$ & $0 \%-19,99 \%$ & $\begin{array}{l}\text { Sangat (Tidak Sesuai/ } \\
\text { Buruk/ Kurang Sekali) }\end{array}$ \\
\hline
\end{tabular}

\section{HASIL DAN PEMBAHASAN}

\section{A. Hasil Tahap Analyze}

Hasil yang didapatkan pada tahap analisis ini adalah teknologi Virtual reality dapat digunakan sebagai solusi untuk membantu menambah wawasan mengenai manusia purbakala secara lebih baik, dengan penerapan teknologi pembelejaran juga akan lebih menarik karena siswa juga dapat berinteraksi dengan teknologi tersebut. Hal ini juga didukung oleh sebagian besar siswa yang tertarik mempelajari sejarah manusia purba di Indonesia dan juga memiliki teknologi pendukung penggunaan virtual reality.

Berdasarkan analisis masalah dan solusi, pada pengembangan aplikasi Virtual reality $3 D$ Pengenalan Manusia Purba bangsa Indonesia untuk SMA kelas $X$ didapatkan beberapa kebutuhan fungsional sebagai berikut, yaitu:

1. Pengguna mampu mempelajari manusia purba dengan memulai penjelajahan dunia Virtual reality.

2. Pengguna mampu menampilkan objek 3D jenis-jenis manusia purba yang ada di Indonesia dan animasi pergerakannya.

3. Pengguna mampu menampilkan informasi terkait manusia purba yang dipilih.

4. Pengguna dapat memainkan game tentang manusia manusia purba

5. Pengguna dapat melihat skor tertinggi game di aplikasi

6. Pengguna mampu menampilkan informasi tentang media dan identitas pengembang dengan menekan tombol tentang.

7. Pengguna dapat mengatur suara

8. Pengguna dapat menutup aplikasi dengan menekan tombol Keluar

Selain itu, terdapat juga beberapa kebutuhan non fungsional dari aplikasi. Kebutuhan non fungsional tersebut yaitu:

1. Usability
Aplikasi memiliki tampilan yang user friendly, tujuannya agar pengguna tidak kesulitan dalam menggunakan aplikasi dan tertarik untuk menggunakan aplikasi.

2. Portability

Aplikasi dapat berjalan pada perangkat dengan sistem operasi Android minimal versi 4.1 (Jelly Bean) dan memiliki sensor gyroscope dan bantuan perangkat keras pendukung Virtual reality seperti Google cardboard.

3. Reliability

Aplikasi tidak dapat diubah oleh pengguna atau pihak lain di luar pengembang.

4. Efficiency

Aplikasi dapat digunakan menggunakan berbagai macam jenis cardboard yang telah banyak tersedia dengan berbagai macam harga.

Untuk mentranslasi kebutuhan perangkat lunak ke representasi desain agar dapat diimplementasikan menjadi program pada tahap selanjutnya diperlukan sebuah perancangan yang menggambarkan permasalahan maupun solusi dari permasalahan. Dalam hal ini pengembang menggunakan diagram, dimana diagram yang digunakan yaitu use case diagram. Use case dari aplikasi Virtual reality $3 D$ Pengenalan Manusia Purba bangsa Indonesia dapat dilihat pada Gambar 3.

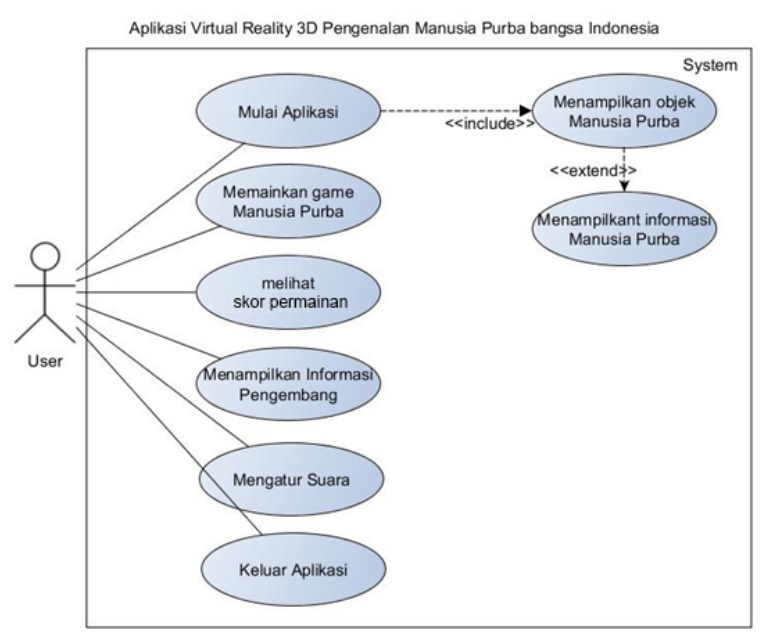

Gambar 3. Use Case Diagram Aplikasi 


\section{B. Hasil Tahap Design}

Hasil yang diperoleh pada tahap desain adalah perancangan skenario aplikasi, perancangan objek manusia purba, perancangan antarmuka perangkat lunak dan perancangan evaluasi tiap tahapan ADDIE. Rancangan evaluasi yang akan dilakukan pada pengembangan aplikasi Virtual reality $3 D$ Pengenalan Manusia Purba bangsa Indonesia untuk SMA kelas $X$ dapat dilihat pada Tabel 3.

Tabel 3. Tabel Rancangan Evaluasi

\begin{tabular}{ccl}
\hline No & \multicolumn{1}{c}{ Tahapan } & \multicolumn{1}{c}{ Evaluasi } \\
\hline $\mathbf{1}$ & Analyze/Analisis & $\begin{array}{l}\text { Uji blackbox (uji } \\
\text { kebenaran proses) }\end{array}$ \\
\hline $\mathbf{2}$ & Design/Desain & $\begin{array}{l}\text { Uji ahli media dan } \\
\text { uji ahli isi }\end{array}$ \\
\hline $\mathbf{3}$ & $\begin{array}{l}\text { Development/ } \\
\text { Pengembangan }\end{array}$ & $\begin{array}{l}\text { Uji white box dan } \\
\text { uji black box (uji } \\
\text { aplikasi dengan } \\
\text { perangkat } \\
\text { berbeda) }\end{array}$ \\
\hline $\mathbf{4}$ & Implementation/ & $\begin{array}{l}\text { Uji pretest, Uji } \\
\text { postest, Uji respon } \\
\text { pengguna, Uji } \\
\text { Implementasi }\end{array}$ \\
& & UEQ \\
\hline
\end{tabular}

\section{Hasil Tahap Development}

Pada tahap development pengembang mulai merancang produk dengan menggunakan perangkat lunak dan perangkat keras yang ada. Pada pengembangan aplikasi ini, arsitektur perangkat lunak yang telah dirancang sedemikian rupa selanjutnya dikembangkan sehingga dapat memenuhi seluruh kebutuhan fungsional yang sudah ditentukan.

Hasil yang diperoleh pada tahap ini diantaranya yaitu rancangan objek manusia dan aplikasi Virtual reality itu sendiri. Berikut adalah beberapa hasil pengembangan dari perancangan aplikasi Virtual reality $3 D$ Pengenalan Manusia Purba bangsa Indonesia untuk SMA kelas $X$ berdasarkan perancangan antarmuka yang telah dilakukan pada tahap desain.

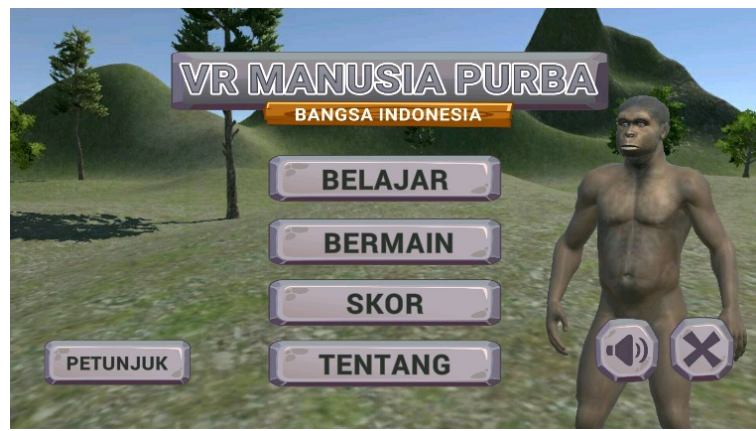

Gambar 4. Hasil antarmuka menu utama

Gambar 4 menunjukkan antarmuka dari menu utama yang menampilkan judul dari game, dan beberapa tombol seperti tombol belajar, bermain, skor, tentang, petunjuk, tombol suara dan tombol untuk keluar.

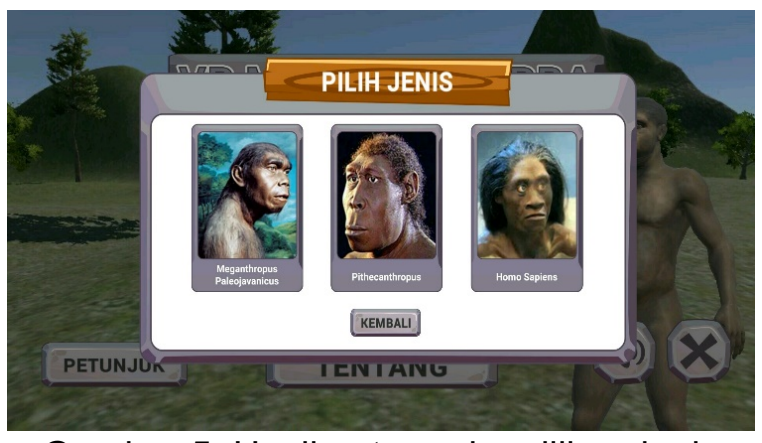

Gambar 5. Hasil antarmuka pilihan jenis manusia purba

Gambar 5 menunjukkan antarmuka pilihan jenis manusia purba yang menampilkan 3 jenis manusia purba yang dapat dipilih. Jenis manusia purba itu diantaranya yaitu Meganthropus, pitechantropus dan homo sapiens.

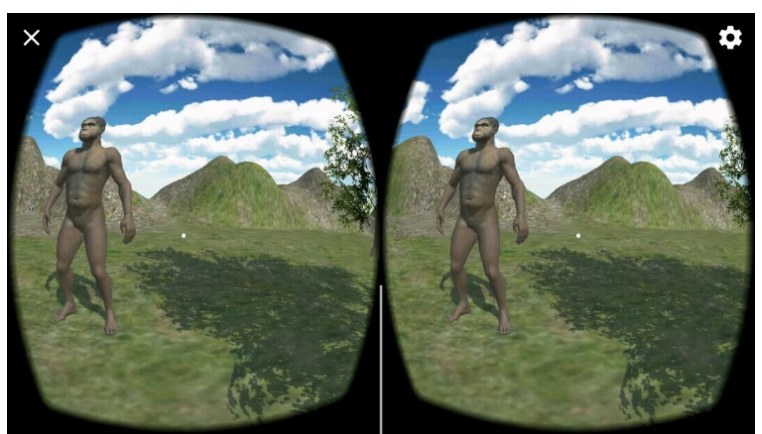

Gambar 6. Hasil antarmuka tampilan VR

Gambar 6 menunjukkan antarmuka tampilan VR yang menampilkan tampilan saat menggunakan Virtual reality dimana layar terbelah menjadi dua. Pengguna harus 
menggunakan perangkat eksternal seperti cardboard untuk melihat tampilan VR.

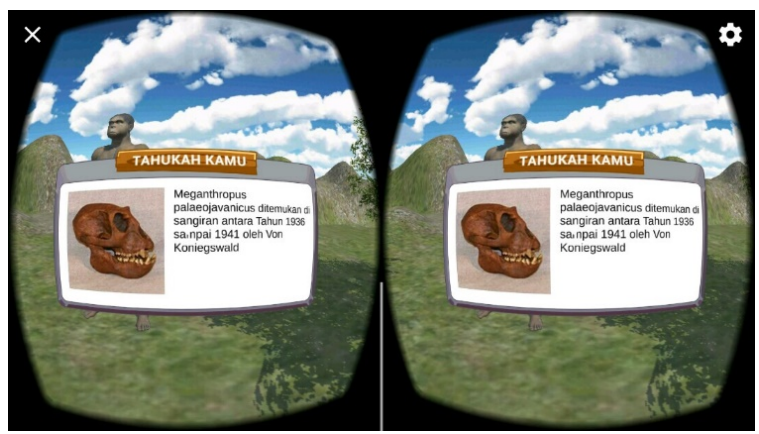

Gambar 7. Hasil rancangan antarmuka informasi manusia purba

Gambar 7 menunjukkan antarmuka Informasi manusia purba yang menampilkan informasi dari manusia purba terpilih. Dalam panel tersebut terdapat keterangan dan foto informasi dari manusia purba.

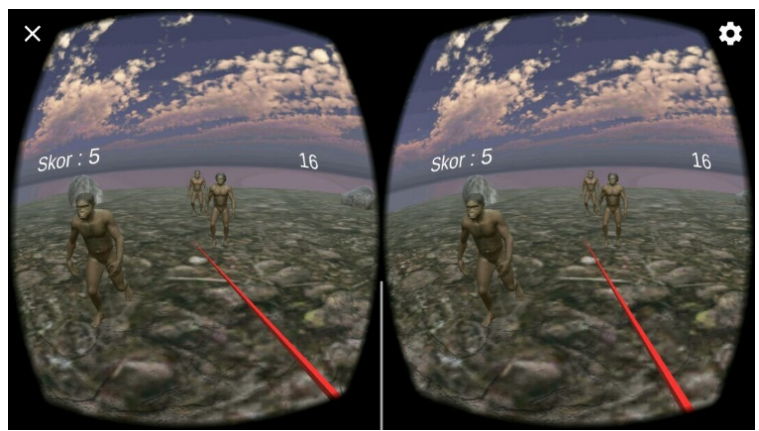

Gambar 8. Hasil antarmuka game manusia purba

Gambar 8 menunjukan antarmuka Game manusia purba yang berisikan permainan berupa beberapa manusia purba yang akan mendatangi pemain. Dalam layar juga terdapat skor dan waktu yang dimiliki pemain, serta pointer penunjuk tembakan

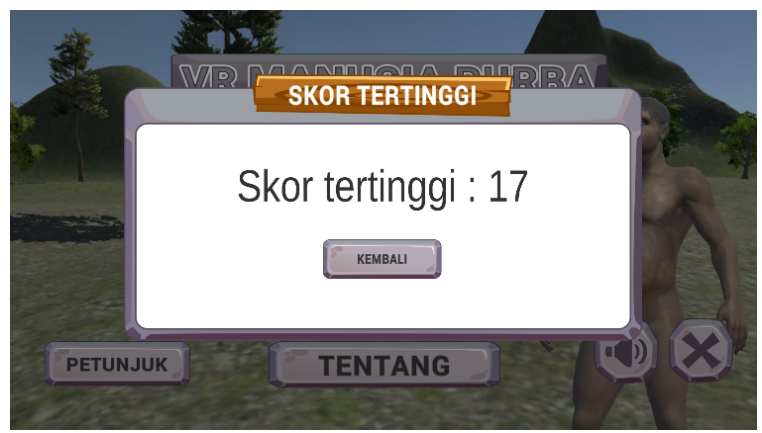

Gambar 9. Hasil antarmuka skor

Gambar 9 menunjukan antarmuka Skor pada menu utama yang menampilkan skor tertinggi yang pernah diraih. Pada antarmuka ini juga ditampilkan tombol untuk mengulang permainan dan tombol untuk pindah ke scene pilihan menu.

\section{Hasil Tahap Implementation}

Pada tahap ini aplikasi telah siap untuk diperkenalkan Aplikasi telah diimplementasikan pada mata pelajaran sejarah di kelas X IPS1, X IPS2 dan X IPS3 SMA Negeri 2 Singaraja. Implementasi dilakukan di kelas pada saat proses pembelajaran berlangsung dan di ruang guru karena keterbatasan waktu yang ada. Penelitian dilakukan dengan menggunakan fasilitas yang telah disediakan yaitu berupa 5 perangkat smartphone, 5 perangkat cardboard dan fasilitas tambahan lainnya. Proses pengambilan data di sekolah dilaksanakan tanggal 25 Februari 2019. Peneliti mengambil 20 orang responden dengan rincian 10 orang siswa kelas X IPS1, 5 orang dari kelas X IPS2 dan 5 orang dari kelas X IPS3.

\section{E. Hasil Tahap Evaluation}

Berdasarkan metode ADDIE, proses evaluasi akan dilaksanakan pada tiap tahap yang telah dilakukan sebelumnya. Evaluasi yang dilakukan berupa pengujian seperti pengujian aplikasi atau penyebaran angket.

\section{a) Evaluasi tahap Analyze}

Pada tahap analyze, hasil yang dievaluasi lebih difokuskan kepada berjalannya kebutuhan fungsional dari aplikasi. Untuk mengevaluasi hal tersebut peneliti melakukan uji kebenaran proses aplikasi dengan menyebar angket. Dari lima angket yang disebar menunjukkan bahwa semua proses dalam aplikasi sudah berjalan dengan baik.

b) Evaluasi tahap Design

Pada tahap design, hasil yang dievaluasi lebih difokuskan kepada evaluasi rancangan tampilan aplikasi dan kualitas teknis. Untuk mengevaluasi hal tersebut, maka peneliti melakukan uji ahli media yang melibatkan dua orang dosen Pendidikan Teknik Infomatika dari Universitas Pendidikan Ganesha. Evaluasi ahli media dilakukan oleh dosen yang pernah mengajarkan mata 
kuliah mengenai Pengolahan Citra Digital dan Komputer Animasi Lanjut (3D). Hasil yang didapatkan dari uji ahli media adalah sebesar $82 \%$, dimana nilai persentase tersebut masuk dalam kriteria "sangat tinggi". Pada uji ahli media terdapat beberapa saran yang diberikan terkait penempatan menu tombol home yang menyulitkan dan saran agar posisi tidak berubah saat melihat informasi. Saran-saran tersebut telah di perbaiki dengan menurunkan tombol home pada scene belajar, dan menonaktifkan fungsi berjalan ketika panel informasi muncul.

Setelah melakukan uji ahli media, tahap evaluasi yang peneliti lakukan selanjutnya adalah uji ahli isi. Evaluasi ahli isi ini memfokuskan penilaian pada isi materi dari aplikasi, pemakaian kata dan bahasa, dan pembelajaran. Peneliti melibatkan ahli yang berprofesi sebagai guru mata pelajaran sejarah di SMA Negeri 2 Singaraja. Ahli tersebut peneliti libatkan sebagai ahli isi pada penelitian ini karena dianggap memiliki konsentrasi di bidang mata pelajaran sejarah, dimana materi manusia purba bangsa Indonesia diajarkan. Hasil yang didapatkan dari uji ahli isi adalah sebesar $96 \%$, dimana nilai persentase tersebut masuk dalam kriteria "sangat tinggi"

\section{c) Evaluasi tahap Development}

Pada tahap development, hasil yang dievaluasi lebih difokuskan kepada berjalan dengan baiknya proses dari aplikasi. Untuk mengevaluasi hal tersebut peneliti melakukan dua pengujian, yaitu uji Whitebox dan Blackbox. Pengujian whitebox dilakukan oleh peneliti sendiri dan untuk pengujian blackbox berfokus pada pengujian aplikasi di perangkat yang berbeda. Perangkat yang diuji diantaranya yaitu xiaomi Redmi 5 Plus, Asus Zenfone 3 dan Oppo, dan dari angket yang disebar menunjukkan bahwa semua proses dalam aplikasi sudah berjalan dengan baik.

\section{d) Evaluasi tahap Implementation}

Pada tahap implementation, terdapat beberapa evaluasi yang dilakukan yang diantaranya yaitu uji kemampuan siswa berupa pretest dan postest, uji respon pengguna dan uji user experience. Jumlah responden yang peneliti gunakan dalam pengujian respon ini adalah 20 orang dengan sebaran sebagai berikut:

a. Siswa kelas X IPS 1: 10 orang

b. Siswa kelas X IPS 2: 5 orang

c. Siswa kelas X IPS 3: 5 orang.

Uji respon Pengguna dilakukan dengan cara penyebaran angket. Berdasarkan perhitungan angket, didapatkan bahwa persentase nilai respon pengguna adalah sebesar $82,3 \%$. Nilai persentase tersebut dalam skala Likert masuk dalam kriteria "sangat tinggi".

Uji pemahaman siswa dilakukan dengan cara pemberian dua buah tes yakni pretest dan postest dengan butir soal yang sama. Pemberian pretest dan postest ini bertujuan untuk mengetahui apakah pengguna dalam hal ini siswa kelas $X$ mengalami peningkatan pengetahuan tentang manusia purba setelah menggunakan Aplikasi yang peneliti kembangkan. Test ini juga dibutuhkan untuk mencari nilai N-gain atau Normalized Gain. Jenis soal yang digunakan adalah soal pilihan ganda dengan jumlah soal sebanyak 20 butir. N-gain dihitung menggunakan rumus sebagai berikut [11]:

$$
\begin{aligned}
& N-\text { gain }=\frac{\text { Skor Pos Test }- \text { Skor Pretest }}{\text { Skor Maksmal }- \text { Skor Pretest }} \\
& N-\text { gain }=\frac{74.75-55.5}{100-55.5} \\
& N-\text { gain }=0.43
\end{aligned}
$$

Berdasarkan pengujian tersebut, didapatkan nilai $\mathrm{N}$-gain sebesar 0,43 sehingga tingkat kenaikan hasil postest masuk ke kriteria "sedang" merujuk pada tabel kriteria normalized gain oleh Hake [11]. Terdapat beberapa alasan mengapa nilai $\mathrm{N}$ gain masuk kriteria sedang, dimana pada penelitian ini salah satu penyebabnya adalah kurangnya waktu siswa dalam menggunakan Aplikasi Virtual reality 3D Pengenalan Manusia Purba Bangsa Indonesia sehingga tidak semua informasi dapat diperoleh siswa. Selain itu butir pertanyaan pada uji pemahaman siswa hanya dapat dijawab jika siswa sudah menggunakan aplikasi secara mendalam. Tabel kriteria N-gain oleh Hake dapat dilihat pada Tabel 3. 
Tabel 3. Tabel Kriteria N-Gain [11]

\begin{tabular}{cc}
\hline Indeks & Kriteria \\
\hline $\mathbf{0 . 7 0}<\mathbf{g}<\mathbf{1 . 0 0}$ & Tinggi \\
\hline $\mathbf{0 . 3 0} \leq \mathbf{g} \leq \mathbf{0 . 7 0}$ & Sedang \\
\hline $\mathbf{0 . 0 0}<\mathbf{g}<\mathbf{0 . 3 0}$ & Rendah \\
\hline
\end{tabular}

Uji user experience dilakukan dengan menggunakan metode UEQ atau User Experience Quistionneir. Hasil dari User Experience Quistionneir didapatkan dengan pengolah data berupa file excel yang dapat diunduh di www. UEQ-online.org. Hasil yang diperoleh dari Uji user experience dapat dilihat pada tabel Tabel 4.

Tabel 4. Hasil uji UX dengan UEQ (www.UEQ-online.org)

\begin{tabular}{ccc}
\hline Scale & Mean & $\begin{array}{c}\text { Comparisson } \\
\text { to benchmark }\end{array}$ \\
\hline Daya tarik & 1.78 & Excellent \\
\hline Kejelasan & 1.74 & Good \\
\hline Efisiensi & 1.60 & Good \\
\hline Ketepatan & 1.59 & Good \\
\hline Stimulasi & 1.63 & Excellent \\
\hline Kebaruan & 1.34 & Good \\
\hline
\end{tabular}

Hasil dari tabel UEQ dapat divisualisasikan seperti Gambar 10.

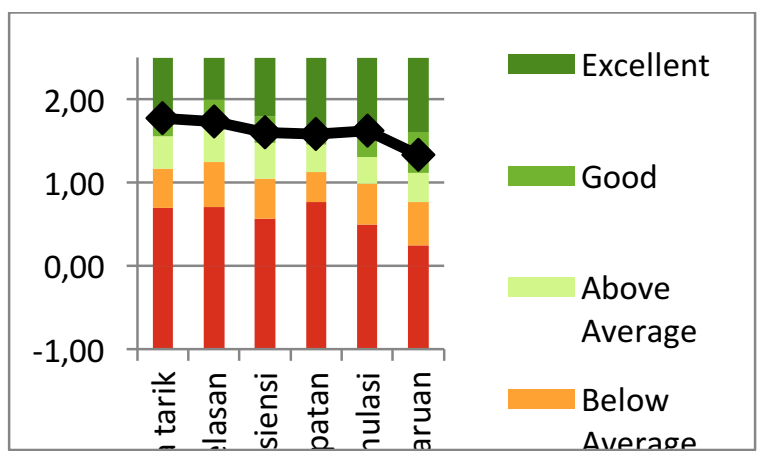

Gambar 10. Grafik hasil uji user experience

Ada beberapa hal yang mempengaruhi nilai dari uji pengalaman pengguna dengan $U E Q$, salah satunya adalah masih banyak dari para siswa yang belum mengerti penggunaan angket dengan skala semantic diferential. Selain itu, beberapa siswa juga belum memahami istilah-istilah yang ada pada angket UEQ.

\section{SIMPULAN}

Berdasarkan hasil analisis, desain, pengembangan, implementasi dan evaluasi pada penelitian ini dapat ditarik kesimpulan bahwa Aplikasi Virtual reality $3 D$ Pengenalan Manusia Purba bangsa Indonesia untuk kelas $X$ membutuhkan perangkat lunak maupun perangkat keras dalam pengembangannya. Aplikasi ini memiliki dua mode yaitu mode belajar dan mode bermain, dimana dalam mode belajar pengguna dapat melihat informasi mengenai jenis manusia purba yang ada di Indonesia. Sedangkan dalam mode bermain, pemain dapat memainkan game tentang manusia purba selama 60 detik. Implementasi Aplikasi Virtual reality $3 D$ Pengenalan Manusia Purba bangsa Indonesia mendapatkan respon yang positif dari pengguna. Dari hasil perhitungan kepada 20 orang siswa, didapatkan bahwa persentase nilai respon pengguna adalah sebesar $82,3 \%$ dengan kriteria "sangat tinggi" dimana pengguna dalam hal ini siswa kelas $X$ SMA dapat menggunakan aplikasi dengan mudah dan sangat tertarik untuk mencoba menggunakan aplikasi ini. Ini juga di dukung dengan hasil yang diperoleh dari uji User Experience menggunakan UEQ dimana hasil yang diperoleh dari 6 komponen penilaian, daya tarik dan stimulasi mendapat nilai sangat baik, sedangkan kejelasan, efisiensi, ketepatan dan kebaruan mendapat nilai baik.

Berdasarkan pengamatan peneliti di lapangan, terdapat beberapa hal yang dapat dijadikan bahan pertimbangan untuk pengembangan berikutnya. Aplikasi ini masih memiliki keterbatasan pada objek dan animasi manusia purba, sehingga untuk pengembangan selanjutnya objek maupun animasi dari manusia purba dapat diperbanyak untuk memberikan pengetahuan yang lebih baik dan lebih menarik. Aplikasi ini juga masih melakukan Loading yang lumayan lama ketika perpindahan ke mode virtual reality. Untuk pengembangan selanjutnya, aplikasi dapat lebih dioptimalkan sehingga meminimalkan waktu Loading. Lingkungan atau environtment dari tiap jenis manusia purba sebaiknya lebih menyesuaikan dengan lingkungan asli untuk tiap jenisnya. Jika 
memiliki informasi yang lebih akurat mengenai lingkungan manusia purba, maka pengembang selanjutnya dapat memperbaiki area dan menambahkan beberapa komponen lain sehingga lebih menyerupai dengan lingkungan asli dari tiap jenis manusia purba yang ada. Lingkungan atau environtment pada mode bermain masih sederhana. Untuk pengembangan selanjutnya, diharapkan lingkungan pada mode bermain lebih menarik dan inovatif. Selain itu juga penerapan aplikasi yang dilakukan masih belum maksimal. Untuk pengembangan selanjutnya, diharapkan agar peneliti lain dapat mengatur waktu yang ada sehingga para siswa dapat menggunakan aplikasi secara maksimal sehingga penilain uji pemahaman siswa juga menjadi lebih baik. Kedepannya, peneliti lain juga dapat lebih menyesuaikan soal pada uji pemahaman agar para siswa bisa menjawab soal tersebut dengan hanya melihat visual dari objek manusia purba yang ada pada aplikasi.

\section{REFERENSI}

[1] Kebudayaan, K. P. (2014). Sejarah Indonesia / Kementerian Pendidikan dan Kebudayaan.-- Edisi Revisi. Jakarta: Kementerian Pendidikan dan Kebudayaan.

[2] Yuana, E. (2014, October). Penemuan Manusia Purba di Indonesia. Retrieved from Eyuana: http://www.eyuana.com/2014/10/penem uan-manusia-purba-di-indonesia_4.html

[3] Sunarni, T., \& Budiarto, D. (2014). Persepsi Efektivitas Pengajaran Bermedia Virtual reality (VR). SEMINAR NASIONAL TEKNOLOGI INFORMASI \& KOMUNIKASI TERAPAN 2014 (SEMANTIK 2014), 179-184.

[4] Khoerniawan, R. W., Agustini, K., \& Putrama, M. (2018). Game Edukasi "Penjelajah" Berbasis Virtual reality. Kumpulan Artikel Mahasiswa Pendidikan Teknik Informatika (KARMAPATI).

[5] Sutanaya, P. Y., Arthana, R., \& Wirawan, A. (2017). Pengembangan Virtual reality Pengenalan Kendaraan Untuk Anak Usia Dini. Jurnal Nasional Pendidikan Teknik Informatika (JANAPATI), 88-95.
[6] Purnomo, F. A., Pratisto, E. H., \& Yasir, R. A. (2016). Pembuatan Ruang Pamer 3D Museum Sangiran Menggunakan Teknologi Virtual reality berbasis Android. Simposium Nasional RAPI XV, 408-413.

[7] Herlangga, K. G. (2016, March 7). Virtual reality dan Perkembangannya. Retrieved from Codepolitan: https://www.codepolitan.com/virtualreality-dan-perkembangannya

[8] Sugiyono. (2012). Metode Penelitian Kuantitatif Kualitatif dan R\&D. Bandung: Alfabeta.

[9] Divayana, D., \& Sugiharni, G. (2016). Evaluasi Program Sertifikasi Komputer pada Universitas Teknologi Indonesia Menggunakan Model CSE-UCLA. Jurnal Pendidikan Indonesia, 835-842.

[10] Tegeh, I. M., Jampel, I. N., \& Pudjawan, K. (2014). Model Penelitian Pengembangan. Yogyakarta: Graha IImu.

[11] Hake, R. (1999). Analyzing Change/Gain Scores. Indiana: Indiana University 